\title{
The Restorative Effect of Apocynin and Catalase in L-Arginine- Induced Hypotension on Normotensive Subjects - the Role of Oxidative Stress
}

\author{
Tan Yong CHIA ${ }^{1}$, Vikneswaran MURUGAIYAH ${ }^{4}$, Munavvar Abdul SATTAR ${ }^{1}$, Nurzalina \\ Abdul KARIM KHAN ${ }^{1}$, Ashfaq AHMAD ${ }^{2,6}$, Mohammed Hadi ABDULLA ${ }^{5}$, Edward James \\ JOHNS $^{5}$, Ho Yoke MEI ${ }^{1}$, Safia AKHTAR ${ }^{3}$, Fiaz Uddin AHMAD ${ }^{7}$
}

${ }^{1}$ Cardiovascular and Renal Physiology Research Laboratory, School of Pharmaceutical Sciences, Universiti Sains Malaysia, Penang, Malaysia, ${ }^{2}$ Department of Pharmacology and Toxicology, School of Medicine, Virginia Commonwealth University, Richmond, VA, USA, ${ }^{3}$ Department of Endocrinology, School of Medicine, University of Virginia, Charlottesville, VA, USA, ${ }^{4}$ Discipline of Pharmacology, School of Pharmaceutical Sciences, Universiti Sains Malaysia, Penang, Malaysia, ${ }^{5}$ Department of Physiology, University College Cork, Cork, Ireland. ${ }^{6}$ Department of Pharmacy, Abasyn University Islamabad Campus, Park Road, Islamabad, Pakistan, ${ }^{7}$ Department of Pharmacy, Islamia University of Bahawalpur, Pakistan

Received December 20, 2019

Accepted September 15, 2020

Epub Ahead of Print November 19, 2020

\section{Summary}

L-arginine is a substrate for nitric oxide synthase (NOS) responsible for the production of NO. This investigation studied the effect of apocynin, an NADPH oxidase inhibitor and catalase, an $\mathrm{H}_{2} \mathrm{O}_{2}$ scavenger on L-arginine-induced oxidative stress and hypotension. Forty Wistar-Kyoto rats were treated for 14 days with vehicle, L-arginine (12.5 mg/ml p.o.), L-arginine + apocynin (2.5 mmol/l p.o.), L-arginine + catalase (10000 U/kg/day i.p.) and L-arginine plus apocynin + catalase respectively. Weekly renal functional and hemodynamic parameters were measured and kidneys harvested at the end of the study for histopathological and renal NADPH oxidase 4 (Nox4) assessments. L-arginine administration in normotensive rats decreased systolic blood pressure $(120 \pm 2$ vs. $91 \pm 2 \mathrm{mmHg}$ ) and heart rate $(298 \pm 21$ vs. $254 \pm 15 \mathrm{bpm})$, enhanced urinary output $(21.5 \pm 4.2$ vs. $32 \pm 1.9 \mathrm{ml} / 24 \mathrm{~h}$, increased creatinine clearance $(1.72 \pm 0.56$ vs. $2.62 \pm 0.40 \mathrm{ml} / \mathrm{min} / \mathrm{kg})$, and fractional sodium excretion ( $0.88 \pm 0.16$ vs. $1.18 \pm 0.16 \%)$, caused proteinuria $(28.10 \pm 1.93$ vs. $35.26 \pm 1.69 \mathrm{mg} / \mathrm{kg} /$ day $)$ and a significant decrease in renal cortical blood perfusion ( $292 \pm 3 \mathrm{vs}$. $258 \pm 5 \mathrm{bpu})$ and pulse wave velocity $(3.72 \pm 0.20$ vs $2.84 \pm 0.13 \mathrm{~m} / \mathrm{s})$ (all $\mathrm{P}<0.05$ ). L-arginine increased plasma malondialdehyde (by 206 \% P<0.05) and NO (by 51 \%, P<0.05) but decreased superoxide dismutase (by $\sim 31 \%, \mathrm{P}<0.05$ ) and total antioxidant
\end{abstract}

capacity (by $\sim 35 \%, \mathrm{P}<0.05$ ) compared to control. Renal Nox4 mRNA activity was approximately 2.1 fold higher $(P<0.05)$ in the L-arginine-treated rats but was normalized by apocynin and apocynin plus catalase treatment. Administration of apocynin and catalase, but not catalase alone to rats fed L-arginine, restored the deranged renal function and structure, prevented hypotension and enhanced the antioxidant capacity and suppressed Nox4 expression. These findings suggest that apocynin and catalase might be used prophylactically in the states of oxidative stress.

\section{Key words}

Apocynin • Catalase $\bullet$ L-arginine $\bullet$ Nitric oxide $\bullet$ Oxidative stress - Hypotension

\section{Corresponding authors}

Tan Yong Chia and Vikneswaran Murugaiyah, Cardiovascular and Renal Physiology Research Laboratory, School of Pharmaceutical Sciences, Universiti Sains Malaysia, 11800, Minden, Penang, Malaysia. E-mail: samual_84@hotmail.com, vicky@usm.my

\section{Introduction}

Nitric oxide (NO) serves as a potent endogenous vasodilator that modulates vascular resistance, renal 
tubular sodium reabsorption, and can act as a neurotransmitter/neuromodulator (Moncada and Higgs 1995). NO is synthesized from the amino acid L-arginine by a family of enzymes called nitric oxide synthases (NOS), via an L-arginine-NO pathway in the presence of oxygen and NADPH. To date, three isoforms of NOS have been identified: neuronal NOS (NOS I or nNOS); inducible NOS (NOS II or iNOS); and endothelial NOS (NOS III or eNOS) (Alderton et al. 2001). All three NOS isoforms are constitutively expressed at relatively low levels but during pathological states, iNOS expression is massively exaggerated and contributes to the decrease in peripheral vascular resistance, hemodynamic instability and hypotension (Zhao et al. 2007). The enzymatic activity of NOS is dependent on binding with calmodulin, which can only occur as a calcium-calmodulin complex with eNOS and nNOS and is regulated by changes in cytoplasmic calcium concentration. Subsequently, the synthesis of NO initiates a signalling pathway involving soluble guanylate cyclase and cyclic guanosine monophosphate (cGMP) (Tousoulis et al. 2012). NO production through the iNOS pathway is responsible for endotoxin-induced tissue injury (Wang et al. 1999) and an NO-mediated decrease in arterial blood pressure. Endotoxaemia is associated with decreased oxidative stress in the heart, aorta and mesenteric artery and the beneficial effects of iNOS inhibitors on endotoxininduced hypotension may be partially due to the restoration of total antioxidant capacity (TuncTan et al. 2006).

L-arginine supplementation ameliorates some deleterious effects in salt-induced hypertension in pregnant rats possibly through the vasodilatory effect of NO and it might also mediate a diuretic-like action (Arikawe et al. 2019). L-arginine has been reported to reduce the progression of left ventricular hypertrophy by reducing oxidative stress and arterial blood pressure (Ahmad et al. 2016). L-arginine acts as a substrate for NOS to generate NO and thereby may contribute to the lowering of systolic blood pressure (Racasan et al. 2004). NO is a potent oxygen free radical scavenger in models of hypertension and chronic renal disease (Wolzt et al. 1997, Ahmad et al. 2018). NO itself may act as a free radical (Beckman and Koppenol 1996, Halliwell et al. 1999) and could lead to toxicity resulting from the diffusion limited reaction of NO with superoxide anion $\left(\mathrm{O}_{2}{ }^{-}\right)$to produce a toxic oxidant peroxynitrite $\left(\mathrm{ONOO}^{-}\right)$ and dinitrogen trioxide (Darley-Usmar et al. 1995). These reactive nitrogen species (RNS) will, in turn, activate guanylate cyclase which is responsible for signal transduction that rapidly acts together with other free radicals mediating both oxidative and nitrosative stressors (Liaudet et al. 2000). Dismutation of $\mathrm{O}_{2}{ }^{--}$via a reaction catalyzed by superoxide dismutase produces hydrogen peroxide $\left(\mathrm{H}_{2} \mathrm{O}_{2}\right)$ which in turn may be fully reduced to $\mathrm{H}_{2} \mathrm{O}$ by a catalase enzyme or partially reduced to hydroxyl radical $\left(\mathrm{HO}^{\circ}\right)$ via the Fenton reaction of iron $\left(\mathrm{Fe}^{2+}\right.$ to $\left.\mathrm{Fe}^{3+}\right)$. This reduction of $\mathrm{O}_{2}^{--}$will contribute to an increase in the steady-state concentration of reactive species which eventually causes damage to cellular components and initiates oxidative stress (Cadenas and Davies 2000).

Oxidative stress plays an important role in the development of vascular complications associated with renal impairments and the beneficial effects of antioxidants may be attributed to increased degradation of reactive oxygen species (Sinha and Kumar Dabla 2015). Apocynin is an NAD(P)H oxidase inhibitor (Impellizzeri et al. 2011, Deng et al. 2016) and one of its beneficial actions may be the reduction of oxidative stress.

The present investigation aimed to evaluate the effect of apocynin, an NAD(P)H oxidase inhibitor, and catalase, an $\mathrm{H}_{2} \mathrm{O}_{2}$ scavenger, on an L-arginine-induced oxidative stress model. The hypotheses to be explored are: firstly, will chronic administration of L-arginine to normotensive Wistar-Kyoto rats cause excess nitric oxide availability in the circulatory system which might induce hypotension and derange renal function. Secondly, whether the chronic administration of L-arginine to normotensive rats would also cause oxidative stress and up-regulation of renal Nox4 mRNA expression. The approach taken was to determine the action of apocynin and catalase to improve blood pressure control, renal hemodynamic and excretory function in normotensive rats over a 14-day period using a prophylactic approach.

\section{Methods}

\section{Experimental animals}

All experimental procedures and protocols were conducted following the approval of the Animal Research and Service Centre (ARASC) of Universiti Sains Malaysia with approval code: USM/IACUC/2017/ (106) (844). Animals were treated in accordance with The Malaysian Code for the Care and Use of Animals for Scientific Purposes (MyCode) which is adapted from the Australian Code for the Care and Use of Animals for Scientific Purposes $-8^{\text {th }}$ Edition published by the 
National Health and Medical Research Council of Australia. A total number of 40 male Wistar Kyoto (WKY) rats (weight $200 \pm 10 \mathrm{~g}$ ) of $8-10$ weeks of age were recruited from the Animal House of Universiti Sains Malaysia and kept in a standard animal facility (temperature $25^{\circ} \mathrm{C}$, humidity $60-70 \%$ ) with a $12 \mathrm{~h}: 12 \mathrm{~h}$ day light-dark cycle provided by the School of Pharmaceutical Sciences, USM.

\section{Preparation of animals}

Animals had free access to rat chow (Gold Coin Sdn. Bhd.) and drinking water. All animals were divided into five groups $(n=8)$ : (1) Control rats which received drinking water as vehicle (C-Veh); (2) L-arginine was dissolved in the drinking water at $12.5 \mathrm{mg} / \mathrm{ml}$ p.o per day; and based on the average volume of fluid intake and animal weight, this equated to about $15 \mathrm{mg} / \mathrm{kg} /$ day (L-arg); (3) L-arginine+apocynin rats were given in drinking water containing both L-arginine, as above, together with $2.5 \mathrm{mmol} / \mathrm{L}$ apocynin, which resulted in an average intake of apocynin of $73 \mathrm{mg} / \mathrm{kg} /$ day (L-arg Apo); (4) L-arg rats treated with catalase (Sigma-Aldrich, St. Louis, MO, USA) at a dose of $10000 \mathrm{U} / \mathrm{kg} /$ day i.p. (L-arg Cat); (5) L-arg treated with a combination of apocynin and catalase (L-arg ApoCat) respectively. Treatments were administered once daily for 14 days and all the drugs were procured from Sigma-Aldrich (St. Louis, MO, USA).

\section{Non-invasive blood pressure measurement}

Weekly systolic blood pressures (SBP) and heart rates (HR) were measured in conscious rats using CODA ${ }^{\circledR}$ tail-cuff plethysmography (Kent Scientific Corporation, Torrington, CT, USA). At each session a total of 10 consecutive readings were selected from each rat and average values were calculated. This method includes acclimatization of the animals to the tail cuff and restrainer system by training them for 5-6 days initially. The temperature of the heating pad was kept constant at $37^{\circ} \mathrm{C}$ and animals were free to move from one side to the other within the restrainer tunnel. Before taking reading in each session, on days 0,7 and 14, the animals were allowed to settle and feel at home before taking the actual readings.

\section{Metabolic and renal functional studies}

The 24-hour metabolic data collection was performed by placing the animals into an individual metabolic cage (Nalgene $\AA$, Thermo Scientific,
Philadelphia, PA, USA). Weekly body weight, water intake and urine volume for all the rats were on days 0,7 and 14, respectively. The $3 \mathrm{ml}$ urine and $1.5 \mathrm{ml}$ of tail vein blood samples were collected and centrifuged at $3500 \mathrm{rpm}$ for $10 \mathrm{~min}$ and the plasma was stored at $-30{ }^{\circ} \mathrm{C}$ for later biochemical analysis. Tail vein blood samples were collected under a conscious state with a topical anesthesia-ethyl chloride spray (Walter Ritter, $\mathrm{GmbH}+\mathrm{Co}$. KG, Germany) applied on the needle stabbing point.

\section{Plasma and urine biochemistry estimations}

Urinary and plasma sodium and potassium levels were analyzed using a flame photometer (Jenway, PFP-7, England, UK) whereas the plasma and urinary creatinine, urinary protein levels were measured using spectrophotometric methods (Power Wave X340, Bio.Tek Instrument Inc., USA). Creatinine clearance $(\mathrm{CrCl})$, fractional excretion of sodium $\left(\mathrm{FE}_{\mathrm{Na}}{ }^{+}\right)$and urinary protein excretion (UPE) were calculated using standard equations.

\section{Acute experimental studies}

All surgical procedures in the terminal studies were performed according to established protocols in our laboratory (Swarup et al. 2010, Ahmad et al. 2014). On day 15 , animals were fasted overnight but allowed a free access to drinking water. The following morning the rats were anesthetized with sodium pentobarbitone $60 \mathrm{mg} / \mathrm{kg}$ (Nembutal®, CEVA, Santé Animale, Libourne, France). A tracheotomy (PE250 tubing, Portex, Kent, UK) was performed to facilitate clear airways, and the left jugular vein was cannulated to enable the administration of supplemental anesthetic (doses of $15 \mathrm{mg} / \mathrm{kg}$ i.v. of sodium pentobarbitone (Nembutal®, CEVA, Santé Animale, Libourne, France) to maintain anesthesia at a constant level during the experiment. For the pulse wave velocity (PVW) measurement, the right carotid artery was catheterized (PE50 tubing, Portex, Kent, UK) and inserted to the level of aortic arch. Another cannula (PE50 tubing, Portex, Kent, UK) was inserted into the abdominal aorta via the left iliac artery. The recording system was linked to a data acquisition system (Powerlab®, AD Instruments, Colorado Springs, CO, USA) via Quad Amp using chart Pro (V.5.5) software. The kidney was exposed via a midline incision and a laser Doppler flow probe (OxyFlow, AD Instruments, Sydney, Australia) was placed in position on the dorsal surface of the exposed left kidney for the measurement of 
renal cortical blood perfusion (RCBP) using a laser Doppler flowmeter (PowerLab®, AD Instruments, Sydney, Australia) which was directly linked to the data acquisition system (PowerLab ${ }^{\circledR}, \mathrm{AD}$ Instruments, Sydney, Australia). The animals were allowed to stabilize for $60 \mathrm{~min}$ after completion of the surgical procedures.

\section{Measurement of pulse wave velocity}

At the end of the study, animals were euthanized with an overdose of sodium pentobarbitone anesthetic (200 mg/kg, Nembutal $\AA$, CEVA, Santé Animale, Libourne, France). The full length of the aorta was exposed and the distance between the tips of the two cannulas was measured $(d)$; the propagation time $(t)$ for the blood pressure wave to travel from aortic arch to abdominal aorta was measured manually by the time delay between the upstroke (foot) of each pressure wave front using the "foot to foot" technique (Wang et al. 2000). Pulse wave velocity (PWV) is the measure of arterial stiffness which indicates arterial endothelial function and is calculated by dividing ' $\mathrm{d}$ ' by ' $\mathrm{t}$ ' and expressed in units of meter per second.

Biochemical analysis of oxidative stress marker and antioxidant enzymes activities

At the end of the experimental protocol, $3 \mathrm{ml}$ of arterial blood was collected via the carotid artery cannula and centrifuged at $3500 \mathrm{rpm}$ for $10 \mathrm{~min}$ to obtain plasma which was then stored at $-30{ }^{\circ} \mathrm{C}$. The plasma samples were analyzed for oxidative stress markers using plasma malondialdehyde (MDA), plasma total superoxide dismutase (T-SOD), plasma nitric oxide (NO) and plasma total antioxidant capacity (T-AOC).

Oxidative stress was accessed using the degree of lipid peroxidation by measuring MDA formation via the thiobarbituric acid reaction (Ohkawa et al. 1979). The antioxidant enzymes, including T-SOD activity in plasma, was determined by the method of Oyanagui (1984). Plasma NO activity was measured using the method described by Archer (1993) and finally the T-AOC in plasma was quantified by the method of Miller et al. (1993). All assay procedures were carried out according to the spectrophotometric kit instructions provided by the manufacturer (Nanjing Jiancheng, Bioengineering Institute, China).

\section{Histology study and kidney index}

Both kidneys were carefully isolated from the circumferential adipose and connective tissues and blotted dry on a piece of laboratory filter paper. The average weight of both kidneys was taken for the estimation of kidney index using the following standard equation: [kidney weight/body weight $\mathrm{x}$ 100].

The left kidney was fixed with $10 \%$ neutral buffered formalin solution (Sigma-Aldrich, St. Louis, Missouri, USA) until histological examination and the contralateral kidney was stored in RNAlater solution (Ambion, Life Technologies, Pleasanton, CA, USA) at $-80{ }^{\circ} \mathrm{C}$ to maintain RNA integrity until processed.

\section{Molecular expression of Nox4 mRNA in kidney}

Molecular analysis of the renal tissue was conducted according to the established protocols in our laboratory (Ahmad et al. 2016). Briefly, kidney tissue was homogenized in $50 \mathrm{mmol} / \mathrm{l}$ ice-cold TRIzole reagent (Ambion, Life Technologies Corporation, USA) and conversion of RNA to cDNA was performed using a High Capacity RNA-to-cDNA kit (Applied Biosystem $^{\mathrm{TM}}$, USA) according to the manufacturer's instructions.

TaqMan primers and probes were used for the gene expression study which had the following accession number; Nox4 gene (GenBank Accession No. AY027527.1 and Rn00585380_m1) and was derived from TaqMan $^{\circledR}$ Gene Expression assays (Applied Biosystems, Waltham, MA, USA). Similarly, the $\operatorname{TaqMan}^{\circledR}$ primer and probe for $\beta$-actin gene (endogenous control) (GenBank Accession No. NM_031144.3 and Rn00667869_m1) was also derived from TaqMan ${ }^{\circledR}$ Gene Expression assays (Applied Biosystems, Waltham, MA, USA) (Kitiyakara et al. 2003). Amplification of the housekeeping enzyme using $\beta$-actin gene (internal control) allowed sample loading and normalization to be determined. The relative quantification of the target gene Nox 4 and internal control $\beta$-actin gene were calculated using comparative $\mathrm{C}_{\mathrm{T}}$ (threshold cycle) method with arithmetic formula ( $2^{-\Delta \Delta C T}$ ) (Livak and Schmittgen 2001). All gene expression assays and procedures were carried out following the instructions of the manufacturer (Applied Biosystems, Waltham, MA, USA).

\section{Statistical analysis}

Data obtained from the metabolic and renal functional studies were analyzed using repeated measures ANOVA. Other data, such as oxidative stress markers, hemodynamics and molecular studies were analyzed with one-way ANOVA followed by the Bonferroni post-hoc test. All the data were presented as mean \pm S.E.M with 
significance at $\mathrm{P}<0.05$ level. GraphPad Prism ${ }^{\circledR}$ Version 2.1 software (GraphPad Software, San Diego, California, USA) was used for statistical analysis.

\section{Results}

Effect of apocynin and catalase on body weight and water intake

As indicated in Table 1, the final body weight on day 14 for all experimental groups was increased significantly $(\mathrm{P}<0.05)$ by comparison to day 0 and day 7 except that L-arg rats experienced a slower body weight gain which was not statistically significant on day 7 . However, L-arg rats which received apocynin and combined apocynin plus catalase treatment significantly $(\mathrm{P}<0.05)$ improved body weight gain by the end of the study.

There were no changes in water intake for any of the experimental groups except that L-arg rats experienced a significantly $(\mathrm{P}<0.05)$ higher water intake on day 14. However, the water intake in L-argApo, L-argCat and L-argApoCat rats were significantly $(\mathrm{P}<0.05)$ lower as compared to the L-arg group of rats.

Effect of apocynin and catalase on systolic blood pressure and heart rate

There was no significant difference in SBP in $\mathrm{C}-\mathrm{Veh}$ rats throughout the study period. However, L-arg rats experienced a significantly $(\mathrm{P}<0.05)$ lower SBP starting from day 7 and progressed until the end of the treatment period. At day 14, the SBP of the L-argApo, L-argCat and L-argApoCat rats was significantly $(\mathrm{P}<0.05)$ elevated compared to the L-arg rats but the SBP value of $\mathrm{L}$-argCat rats remained significantly $(\mathrm{P}<0.05)$ lower than their L-argApo and L-argApoCat counterparts. On the other hand, a similar pattern was also manifested in the heart rate parameter except that the L-argCat rats had a significantly $(\mathrm{P}<0.05)$ lower heart rate on day 14 as compared to day 0 . However, this pattern of response was not manifested in the SBP of L-argCat rats (Table 1).

Effect of apocynin and catalase on renal functional parameters

A 24-hour measurement of urine output was made on days 0,7 and 14 . There was no significant change of urine output in any of the experimental rats from day 0 to day 7 . However, on day 14 , the urine output volume of the L-arg rats was significantly $(\mathrm{P}<0.05)$ increased compared to the $\mathrm{C}-\mathrm{Veh}$ rats. By contrast, on day 14 the urine output volume of L-argApo, L-argCat and L-argApoCat rats was significantly $(\mathrm{P}<0.05)$ lower compared to the $\mathrm{L}$-arg rats (Table 1$)$.

Creatinine clearance and fractional excretion of sodium were significantly $(\mathrm{P}<0.05)$ higher in L-arg rats starting from day 7 until day 14 compared to $\mathrm{C}$-Veh rats but was unchanged in the L-argApo, L-argCat and L-argApoCat rats which were significantly $(\mathrm{P}<0.05)$ lower compared to the L-arg counterparts (Table 1).

The urinary sodium to urinary potassium ratio of the L-arg rats was significantly $(\mathrm{P}<0.05)$ higher compared to $\mathrm{C}$-Veh rats on day 14 . Treatment with apocynin, catalase and combination of apocynin and catalase in L-arg rats significantly $(\mathrm{P}<0.05)$ lowered the urinary sodium to urinary potassium ratio (Table 1).

Similarly, the urinary protein excretion of L-arg rats was also significantly $(\mathrm{P}<0.05)$ higher when compared to $\mathrm{C}$-Veh rats but only L-argApo and L-argApoCat rats exhibited a significantly $(\mathrm{P}<0.05)$ lower urinary protein excretion value. Although the urinary protein excretion of L-argCat rats was lower than their L-arg counterpart but this did not reach a statistically significant level (Table 1).

The kidney index of the L-arg rats was significantly $(\mathrm{P}<0.05)$ augmented as compared to untreated $\mathrm{C}$-Veh rats but was prevented $(\mathrm{P}<0.05)$ in the L-argApo and L-argCat groups of rats. However, combined apocynin and catalase treatment ameliorated the increase in kidney index observed in the L-argininetreated rats although it did not reach statistical significance (Table 1).

\section{Effect of apocynin and catalase on baseline hemodynamic} parameters

Table 2 showed the baseline renal cortical blood perfusion (RCBP) of the L-arg rats was significantly $(\mathrm{P}<0.05)$ lower than $\mathrm{C}-\mathrm{Veh}$ rats. However, the L-argApo group had a significantly $(\mathrm{P}<0.05)$ higher baseline RCBP as compared to L-arg rats. On the other hand, the baseline RCBP in the L-argCat rats was significantly $(\mathrm{P}<0.05)$ lower than their C-Veh, L-argApo and L-argApoCat counterparts.

The PWV value of the L-arg rats was significantly $(\mathrm{P}<0.05)$ lower than the $\mathrm{C}-\mathrm{Veh}$ rats and although the PWV value of the L-argApo, L-argCat rats was slightly higher than their L-arg counterparts, it was only significant $(\mathrm{P}<0.05)$ in the $\mathrm{L}-\arg A$ poCat group of rats. 
Table 1. Weekly body weight, blood pressure and renal functional parameters during 14-day study period in control (C-Veh), L-arginine-treated (L-arg), L-arg treated with apocynin (L-argApo), L-arg treated with catalase (L-argCat) and L-arg treated with apocynin plus catalase (L-argApoCat) rats. Data presented as mean \pm SEM. $* p<0.05$ vs. Day $0 ; \# p<0.05$ vs. C-Veh; $† p<0.05$ vs. L-arg; $p<0.05$ vs. L-argApoCat; $\delta p<0.05$ vs. L-argApo.

\begin{tabular}{|c|c|c|c|c|c|c|c|}
\hline \multirow{4}{*}{$\begin{array}{l}\text { Parameter } \\
\text { Body Weight } \\
\text { (g) }\end{array}$} & \multirow{3}{*}{$\begin{array}{l}\text { Group } \\
\text { C-Veh }\end{array}$} & \multirow{3}{*}{$\begin{array}{l}\mathbf{n} \\
8\end{array}$} & \multirow{3}{*}{$\begin{array}{r}\mathbf{0} \\
204.7 \pm 1.5\end{array}$} & \multicolumn{2}{|c|}{ Day } & \multirow{2}{*}{\multicolumn{2}{|c|}{14}} \\
\hline & & & & \multicolumn{2}{|l|}{7} & & \\
\hline & & & & $229.4 \pm 3.9$ & \multirow[t]{2}{*}{$*$} & $251.2 \pm 3.6$ & $*$ \\
\hline & L-arg & 8 & $210.7 \pm 2.3$ & $225.0 \pm 4.9$ & & $239.2 \pm 2.5$ & $*$ \\
\hline & L-argApo & 8 & $209.1 \pm 3.1$ & $227.5 \pm 5.2$ & $*$ & $258.6 \pm 8.2$ & $* \dagger$ \\
\hline & L-argCat & 8 & $204.1 \pm 3.6$ & $230.0 \pm 5.1$ & $*$ & $248.2 \pm 4.3$ & $*$ \\
\hline & L-argApoCat & 8 & $209.8 \pm 3.2$ & $235.9 \pm 5.1$ & $*$ & $265.8 \pm 4.9$ & $* \dagger$ \\
\hline \multirow{5}{*}{$\begin{array}{l}\text { Water Intake } \\
(\mathrm{ml} / 24 \mathrm{~h})\end{array}$} & C-Veh & 8 & $35.8 \pm 2.8$ & $36.3 \pm 5.7$ & & $38.0 \pm 3.4$ & \\
\hline & L-arg & 8 & $38.3 \pm 1.2$ & $35.5 \pm 2.1$ & & $56.2 \pm 2.0$ & $* \#$ \\
\hline & L-argApo & 8 & $36.5 \pm 1.9$ & $40.3 \pm 5.2$ & & $41.5 \pm 3.1$ & $\dagger$ \\
\hline & L-argCat & 8 & $37.7 \pm 2.0$ & $38.5 \pm 1.9$ & & $35.7 \pm 1.4$ & $\dagger$ \\
\hline & L-argApoCat & 8 & $36.2 \pm 1.8$ & $38.3 \pm 4.2$ & & $35.3 \pm 3.0$ & $\dagger$ \\
\hline \multirow{5}{*}{$\begin{array}{l}\text { Systolic Blood } \\
\text { Pressure } \\
(\mathrm{mmHg})\end{array}$} & C-Veh & 8 & $115 \pm 1$ & $117 \pm 1$ & \multirow{5}{*}{$*$} & $120 \pm 2$ & \\
\hline & L-arg & 8 & $116 \pm 3$ & $95 \pm 3$ & & $91 \pm 2$ & $* \#$ \\
\hline & L-argApo & 8 & $117 \pm 1$ & $122 \pm 3$ & & $126 \pm 1$ & $\dagger$ \\
\hline & L-argCat & 8 & $115 \pm 2$ & $104 \pm 1$ & & $107 \pm 2$ & $\dagger \uparrow \delta$ \\
\hline & L-argApoCat & 8 & $116 \pm 2$ & $118 \pm 4$ & & $124 \pm 3$ & $\dagger$ \\
\hline \multirow{5}{*}{$\begin{array}{l}\text { Heart Rate } \\
(\text { bpm) }\end{array}$} & C-Veh & 8 & $300 \pm 11$ & $301 \pm 12$ & \multirow{5}{*}{$*$} & $298 \pm 21$ & \\
\hline & L-arg & 8 & $299 \pm 13$ & $274 \pm 11$ & & $254 \pm 15$ & $* \#$ \\
\hline & L-argApo & 8 & $304 \pm 15$ & $295 \pm 12$ & & $290 \pm 21$ & $\dagger$ \\
\hline & L-argCat & 8 & $302 \pm 21$ & $295 \pm 15$ & & $279 \pm 12$ & $* \dagger \uparrow \delta$ \\
\hline & L-argApoCat & 8 & $295 \pm 24$ & $298 \pm 24$ & & $305 \pm 23$ & $\dagger$ \\
\hline \multirow{5}{*}{$\begin{array}{l}\text { Urine Output } \\
(\mathrm{ml} / 24 \mathrm{~h})\end{array}$} & C-Veh & 8 & $19.8 \pm 1.3$ & $23.3 \pm 4.3$ & & $21.5 \pm 4.2$ & \\
\hline & L-arg & 8 & $19.0 \pm 0.7$ & $24.2 \pm 2.2$ & & $32.0 \pm 1.9$ & $* \#$ \\
\hline & L-argApo & 8 & $19.3 \pm 0.3$ & $23.7 \pm 2.2$ & & $24.3 \pm 2.3$ & $\dagger$ \\
\hline & L-argCat & 8 & $20.5 \pm 1.8$ & $16.5 \pm 6.7$ & & $20.7 \pm 3.5$ & $\dagger$ \\
\hline & L-argApoCat & 8 & $19.2 \pm 1.2$ & $21.0 \pm 2.5$ & & $22.7 \pm 2.8$ & $\dagger$ \\
\hline \multirow{5}{*}{$\begin{array}{l}\text { Creatinine } \\
\text { Clearance } \\
(\mathrm{ml} / \mathrm{min} / \mathrm{kg})\end{array}$} & C-Veh & 8 & $1.65 \pm 0.37$ & $1.62 \pm 0.46$ & \multirow{5}{*}{$*$} & $1.72 \pm 0.56$ & \\
\hline & L-arg & 8 & $1.75 \pm 0.26$ & $2.98 \pm 0.64$ & & $2.62 \pm 0.40$ & $* \#$ \\
\hline & L-argApo & 8 & $1.79 \pm 0.60$ & $1.86 \pm 0.13$ & & $1.94 \pm 0.71$ & $\dagger$ \\
\hline & L-argCat & 8 & $1.82 \pm 0.13$ & $1.74 \pm 0.33$ & & $1.89 \pm 0.44$ & $\dagger$ \\
\hline & L-argApoCat & 8 & $1.81 \pm 0.59$ & $1.94 \pm 0.78$ & & $1.97 \pm 0.66$ & $\dagger$ \\
\hline \multirow{5}{*}{$\begin{array}{l}\text { Fractional } \\
\text { Excretion of } \\
\text { Sodium } \\
(\%)\end{array}$} & C-Veh & 8 & $0.80 \pm 0.08$ & $0.93 \pm 0.13$ & \multirow{5}{*}{$*$} & $0.88 \pm 0.16$ & \\
\hline & L-arg & 8 & $0.81 \pm 0.10$ & $1.12 \pm 0.22$ & & $1.18 \pm 0.16$ & *\# \\
\hline & L-argApo & 8 & $0.90 \pm 0.38$ & $0.81 \pm 0.30$ & & $0.75 \pm 0.15$ & $\dagger$ \\
\hline & L-argCat & 8 & $0.80 \pm 0.07$ & $0.84 \pm 0.07$ & & $0.87 \pm 0.12$ & $\dagger$ \\
\hline & L-argApoCat & 8 & $0.86 \pm 0.13$ & $0.78 \pm 0.15$ & & $0.73 \pm 0.08$ & $\dagger$ \\
\hline
\end{tabular}


Table 1. (continued)

\begin{tabular}{|c|c|c|c|c|c|c|}
\hline \multirow[t]{5}{*}{$U N a^{+}: U K^{+}$ratio } & C-Veh & 8 & $0.26 \pm 0.02$ & $0.25 \pm 0.02$ & $0.28 \pm 0.02$ & \\
\hline & L-arg & 8 & $0.27 \pm 0.01$ & $0.34 \pm 0.01$ & $0.36 \pm 0.03$ & $* \#$ \\
\hline & L-argApo & 8 & $0.25 \pm 0.01$ & $0.28 \pm 0.02$ & $0.27 \pm 0.01$ & $\dagger$ \\
\hline & L-argCat & 8 & $0.29 \pm 0.01$ & $0.27 \pm 0.01$ & $0.26 \pm 0.01$ & $\dagger$ \\
\hline & L-argApoCat & 8 & $0.26 \pm 0.01$ & $0.28 \pm 0.05$ & $0.28 \pm 0.02$ & $\dagger$ \\
\hline \multirow{5}{*}{$\begin{array}{l}\text { Urinary Protein } \\
\text { Excretion } \\
(\mathrm{mg} / \mathrm{kg} / \text { day })\end{array}$} & C-Veh & 8 & $28.53 \pm 2.45$ & $29.60 \pm 1.41$ & $28.10 \pm 1.93$ & \\
\hline & L-arg & 8 & $28.09 \pm 1.05$ & $30.95 \pm 3.35$ & $35.26 \pm 1.69$ & *\# \\
\hline & L-argApo & 8 & $28.13 \pm 1.20$ & $30.84 \pm 2.14$ & $29.75 \pm 3.24$ & $\dagger$ \\
\hline & L-argCat & 8 & $28.56 \pm 2.51$ & $29.83 \pm 3.35$ & $30.98 \pm 2.80$ & \\
\hline & L-argApoCat & 8 & $28.52 \pm 1.85$ & $28.53 \pm 2.47$ & $28.74 \pm 3.53$ & $\dagger$ \\
\hline \multirow{5}{*}{$\begin{array}{l}\text { Kidney Index } \\
(\%)\end{array}$} & C-Veh & 8 & - & - & $0.33 \pm 0.01$ & \\
\hline & L-arg & 8 & - & - & $0.40 \pm 0.01$ & \# \\
\hline & L-argApo & 8 & - & - & $0.33 \pm 0.01$ & $\dagger$ \\
\hline & L-argCat & 8 & - & - & $0.38 \pm 0.01$ & \\
\hline & L-argApoCat & 8 & - & - & $0.35 \pm 0.03$ & \\
\hline
\end{tabular}

Table 2. Baseline hemodynamic parameters measured at the end of the experiment on Day 14 in control (C-Veh), L-arginine-treated (L-arg), L-arg treated with apocynin (L-argApo), L-arg treated with catalase (L-argCat) and L-arg treated with apocynin plus catalase (L-argApoCat) rats. Data presented as mean \pm SEM. $¥ p<0.05$ vs. C-Veh of all except L-arg; \# $p<0.05$ vs. C-Veh; $+p<0.05$ vs. L-arg; $\mathrm{p}<0.05$ vs. L-argApoCat; $\delta \mathrm{p}<0.05$ vs. L-argApo.

\begin{tabular}{lccccc}
\hline Parameter & C-Veh & L-arg & $\begin{array}{c}\text { Group (all n=8) } \\
\text { L-argApo }\end{array}$ & L-argCat & L-argApoCat \\
\hline$R C B P(\mathrm{bpu})$ & $292 \pm 3$ & $258 \pm 5 \#$ & $280 \pm 6 \dagger$ & $239 \pm 8 ¥ \Phi$ & $279 \pm 5$ \\
$P W V(\mathrm{~m} / \mathrm{s})$ & $3.72 \pm 0.20$ & $2.84 \pm 0.13 \#$ & $3.50 \pm 0.31$ & $3.34 \pm 0.24$ & $3.65 \pm 0.12^{\dagger}$ \\
\hline
\end{tabular}

Effect of apocynin and catalase on oxidative stress parameters

The plasma MDA concentration was significantly higher in L-arg rats compared to C-Veh, L-argApo, L-argCat and L-argApoCat rats (all $\mathrm{P}<0.05$ ). On the other hand, treatment with apocynin or catalase alone or combination of apocynin and catalase significantly decreased (all $\mathrm{P}<0.05$ ) the MDA levels compared to L-arg treated rats. However, the plasma MDA level in L-argCat rats was significantly $(\mathrm{P}<0.05)$ higher than their L-argApo and L-argApoCat counterparts (Fig. 1A).

Plasma T-SOD level was significantly $(\mathrm{P}<0.05)$ lower in L-arg rats as compared to $\mathrm{C}$-Veh rats. By contrast, treatment of L-arg rats with apocynin or catalase alone or combination apocynin and catalase successfully raised the plasma T-SOD levels similar to those found in
C-Veh rats (all $\mathrm{P}<0.05)$ (Fig. 1B).

Plasma NO of the L-arg rats was significantly $(\mathrm{P}<0.05)$ higher than their $\mathrm{C}-\mathrm{Veh}$ rats. Nevertheless, the plasma NO of L-arg rats which received apocynin or catalase alone or combination of apocynin and catalase treatment was significantly $(\mathrm{P}<0.05)$ lower than their L-arg counterparts. However, the plasma NO levels of L-argCat rats was still significantly $(\mathrm{P}<0.05)$ higher than the L-argApo and L-argApoCat rats (Fig. 1C).

The plasma level of T-AOC was significantly $(\mathrm{P}<0.05)$ lower in $\mathrm{L}$-arg rats as compared to $\mathrm{C}-\mathrm{Veh}$ rats. On the other hand, the plasma levels of T-AOC were significantly (all $\mathrm{P}<0.05$ ) increased in the $\mathrm{L}$-argApo, $\mathrm{L}$-argCat and L-argApoCat rats as compared to their L-arg counterparts. However, the T-AOC levels in L-argCat rats still significantly $(\mathrm{P}<0.05)$ lower than L-argApoCat (Fig. 1D). 
A

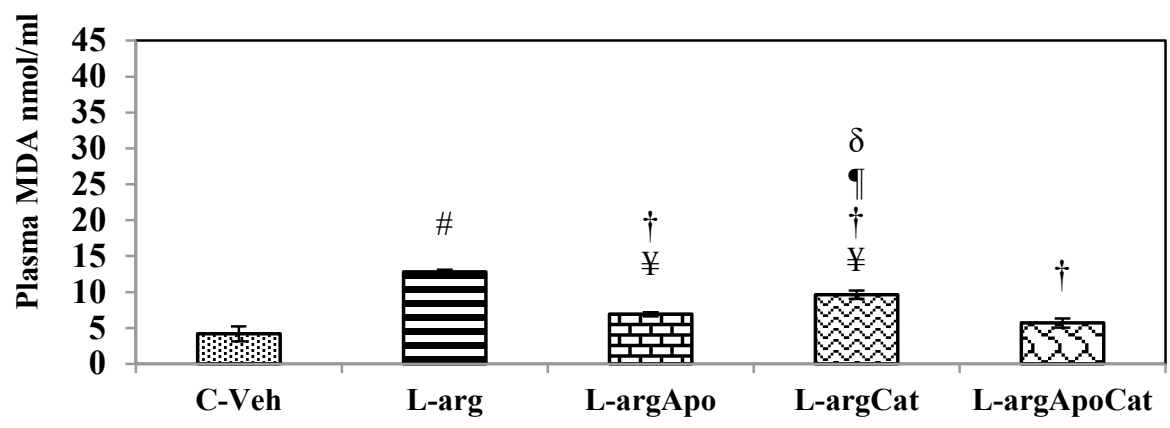

B

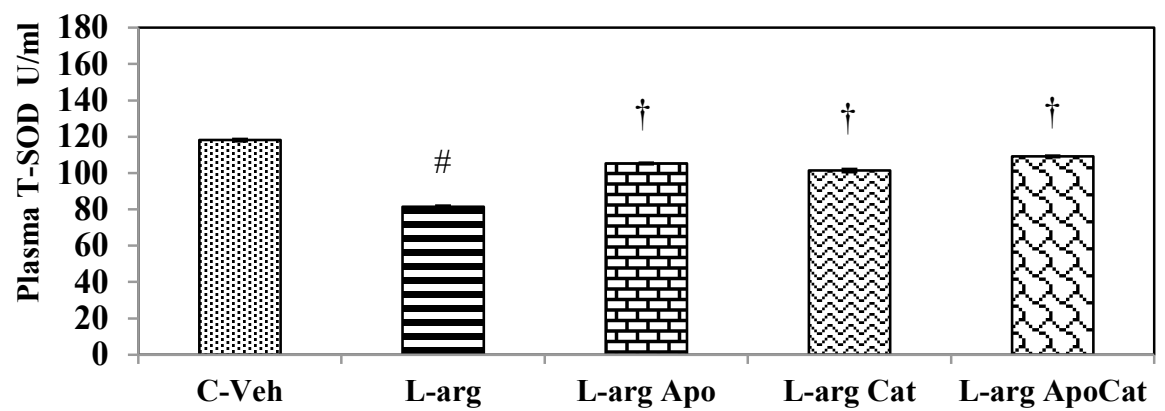

C

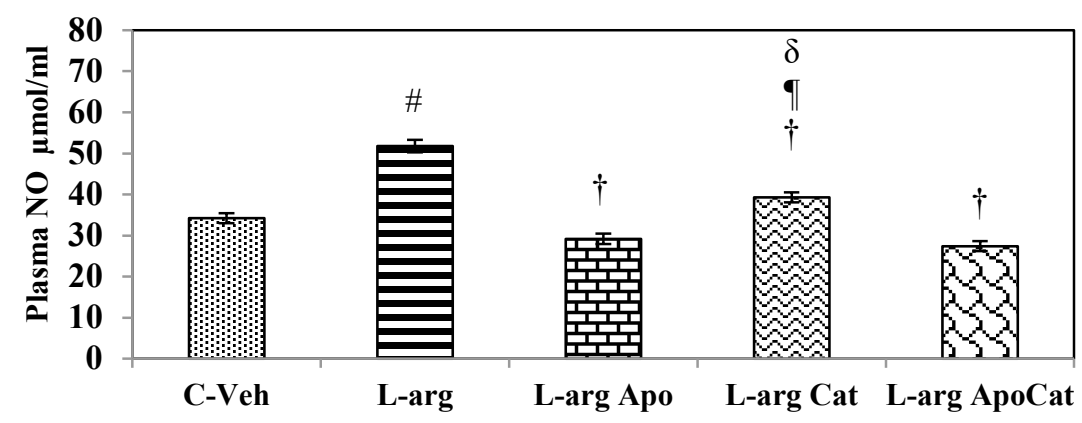

D

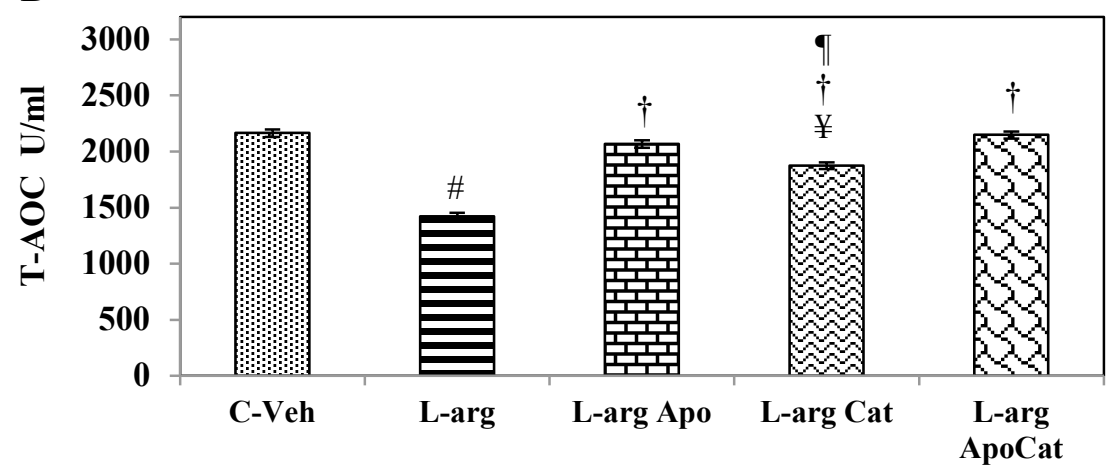

Fig. 1. Biochemical analysis of oxidative stress markers. Plasma levels of MDA (A), T-SOD activity (B), NO (C) and total AOC (D) were measured in control (C-Veh), L-arginine treated (L-arg), L-arginine treated with apocynin (L-argApo), L-arginine treated with catalase (L-argCat) and L-arginine treated with apocynin plus catalase (L-argApoCat) rats. Data presented as mean \pm SEM on Day 14. $¥ p<0.05$ vs. C-Veh of all except L-arg; \# $p<0.05$ vs. C-Veh; † $\mathrm{p}<0.05$ vs. L-arg; $9 \mathrm{p}<0.05$ vs. L-argApoCat; $\delta \quad p<0.05 \quad$ vs. L-argApo. 


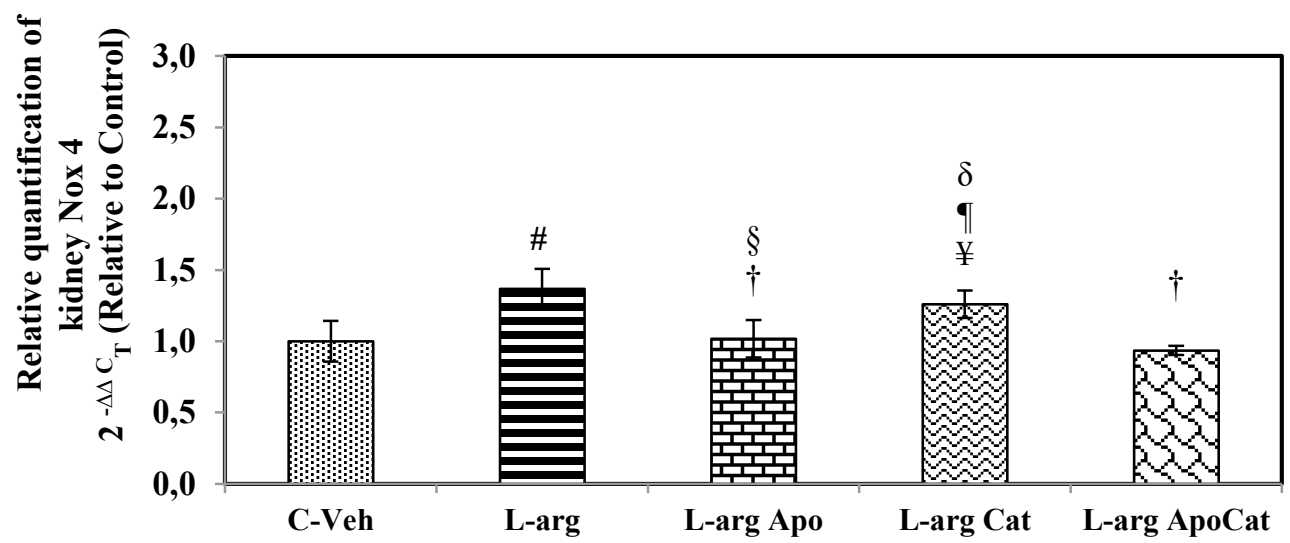

Fig. 2. The molecular expression of Nox 4 mRNAs activity in the renal tissue homogenate of control (C-Veh), L-arginine-treated (L-arg), $\mathrm{L}$-arg treated with apocynin (L-argApo), L-arg treated with catalase (L-arg Cat) and L-arg treated with apocynin plus catalase (L-argApoCat) rats. Data presented as mean \pm SEM on Day 14. $¥ p<0.05$ vs. C-Veh of all except L-arg; \# $p<0.05$ vs. C-Veh; $\dagger p<0.05$ vs. L-arg; I $p<0.05$ vs. L-argApoCat; $\delta p<0.05$ vs. L-argApo.

Effect of apocynin and catalase on the molecular expression of renal Nox 4 mRNA expression

L-arginine administration resulted in a $\sim 37 \%$ up-regulation of Nox 4 mRNA in the renal tissue of L-arg group compared to that in the $\mathrm{C}-\mathrm{Veh}$ group of rats $(\mathrm{P}<0.05)$. Treatment of $\mathrm{L}$-arg rats with apocynin resulted in a $35 \%$ decrease in Nox 4 mRNA when compared to Larg rats $(\mathrm{P}<0.05)$. On the other hand, treatment of $\mathrm{L}$-arg rats with catalase resulted an $8 \%$ down-regulation of Nox 4 mRNA in the renal tissue compared to L-arg rats $(\mathrm{P}<0.05)$. Moreover, combined apocynin and catalase treatment in the L-arg rats decreased $(\mathrm{P}<0.05)$ the Nox4 mRNA expression by $32 \%$ compared to L-arg counterparts (Fig. 2).

\section{Histopathology evidence}

The kidney tissue of L-arg rats showed a prominent mild arteriolar congestion in the glomerulus and mild ischemic damage in the tubular area as shown in (Fig. 3B). However, treatment with apocynin in the L-arg rats resulted in relatively normal glomerular and tubular structures. Blood vessels and parenchyma were also normal as shown in (Fig. 3C). On the other hand, treatment with catalase in L-arg rats caused a mild arteriolar congestion in the glomerular area with minimal tubular congestion as shown in Figs 3D and 3E. Interestingly, L-arg rats which received combined apocynin and catalase treatment did not demonstrate any ultra-structural changes in their kidney tissue as shown in Fig. 3F.

\section{Discussion}

The main finding in this study was that the oral administration of L-arginine to normotensive WistarKyoto rats caused a derangement in renal hemodynamic, renal functional and a decrease in both blood pressure and pulse wave velocity. L-arginine administration was also associated with an increase in oxidative stress markers in plasma, Nox4 expression in the kidney together with renal structural changes. Concomitant administration of the NAD $(\mathrm{P}) \mathrm{H}$ blocker, apocynin, ameliorated most of the L-arginine-induced changes in renal function, cardiovascular status and oxidative stress variables whilst catalase administration appeared to be less effective. Co-administration of apocynin and catalase resulted in a suppression of the L-arginine-induced responses similar to those of apocynin alone. Together these findings would suggest that it is the generation of excess NO, rather than a concomitant scavenging of ROS, which underlies the renal functional and structural responses to L-arginine.

In the present study, body weight gain in L-arginine-treated rats was slower than that of their control untreated counterparts by approximately $5 \%$. In addition, the water intake in L-arginine-treated rats was increased by $48 \%$. The exact reason behind the slower body weight gain and the development of polydipsia in L-arginine-treated rats was unclear but it could be possibly contributed to excess production of NO which could potentially inhibit glycolysis in the mitochondrial respiratory chain leading to a malfunction in energy absorption (Darley-Usmar et al. 1995). Alternatively, the slower body weight gain could be due to catabolism of body fat as L-arginine supplementation promotes muscle gain but reduces body fat accretion (Tan et al. 2009). Water intake in L-arginine-treated rats was markedly increased accompanied by a proportional elevation in 

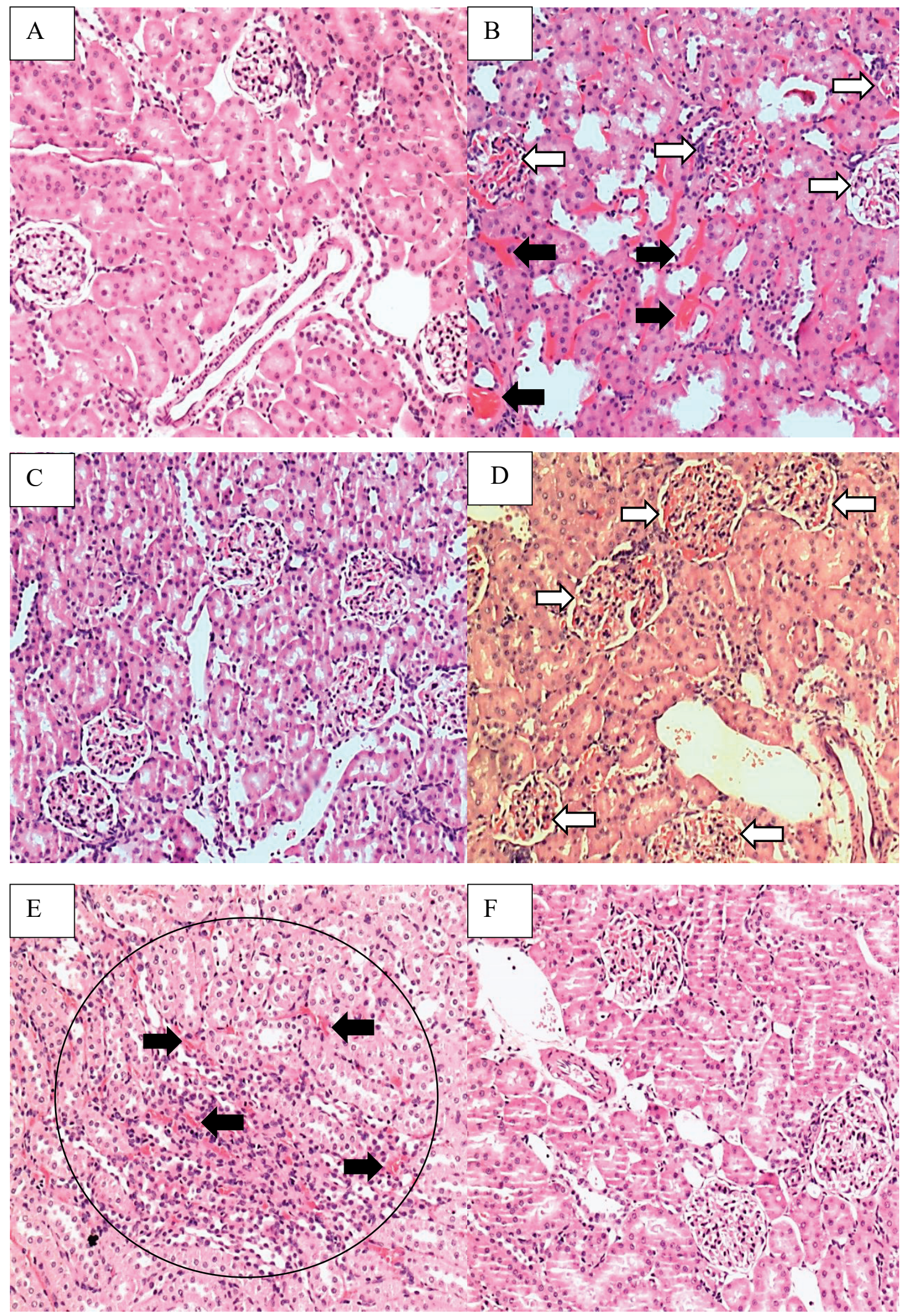

Fig. 3. Histopathological study of rat renal tissue. The renal tissue of C-Veh $[\mathbf{A}], \mathrm{L}-\operatorname{argApo}[\mathbf{C}]$ and L-argApoCat $[\mathbf{F}]$ rats showed normal glomerular and tubular structures. However, there was a prominent mild arteriolar constriction found in the glomeruli (open arrow) and a mild ischemic damage in the tubular area (solid arrow) in the kidney of L-arg rats [B]. Similarly, a mild arteriolar congestion (open arrow) in the glomeruli [D] and a minimal ischemic tubular congestion (solid arrow) was also manifested in the renal tissue of L-argCat rats $[\mathbf{E}]$. (Hematoxylin and eosin stain; original magnification $\mathrm{x} 10$ ) 
urinary excretion. This suggests that L-arginine administration enhanced diuretic activity in the kidney. There is evidence that L-arginine supplementation can, via NO, cause an enhanced aquaporin-2 (AQP2) expression in the renal outer medulla of streptozotocindiabetic rats (Ortiz et al. 2014), which would increase urine excretion.

L-arginine has an acute hypotensive effect in normotensive human subjects (Kanno et al. 1992) which has been presumed to be the result of increased L-arginine metabolism by endothelial NOS to increase NO production (Mehta et al. 1996). These reports are in agreement with the present findings where the administration of L-arginine in normotensive rats decreased systolic blood pressure and heart rate. The lower heart rate in L-arginine-treated rats could be due to a reduction in sympathetic activity in this model as previously observed (Okamoto et al. 1994, Kaur et al. 2017) as it has been reported that sympathetic tone is enhanced in rats with L-NAME-induced hypertension which is a model of severe NO deficiency (Sander et al. 1997, Pechanova et al. 2004). Together, these reports would support the findings of the present study in that an attenuation of sympathetic tone, consequent to elevated NO production, would decrease systolic blood pressure.

The patterns of reduced weight gain and increased water balance in the face of reduced systolic blood pressure and heart rate following the treatment with L-arginine were largely restored to normal values by administration of a combination of apocynin and catalase. The normalisation of blood pressure by apocynin alone and together with catalase supports a previous report on an oxidative stress induced hypertension model (Touyz 2008). Although increased oxidative stress is a major component of hypertension ( $\mathrm{Hu}$ et al. 2006, Wedgwood et al. 2011), the current L-arginine-induced hypotension model led to a state of oxidative stress characterized by the raised of plasma MDA levels and reduction in plasma T-AOC enzymes. The normalization of blood pressure and heart rate could be due to the antioxidant actions of apocynin and catalase which inhibit ROS/RNS generation by NADPH oxidases and ROS scavenging pathways.

Previous studies in animals and man reported that L-arginine treatment increased glomerular filtration rate, enhanced urinary albumin excretion and caused a natriuresis (Herlitz et al. 1999, Zhou et al. 2001). The present findings are in line with previous reports where urine output was greatly increased following L-arginine administration. There was also a marked increase in fractional sodium excretion and creatinine clearance in response to the 14 days of L-arginine treatment. The possibility arises that the enhanced natriuretic activity in this L-arginine model could, in part, contribute to the hypotensive response due to the increased loss of sodium and water. Another potential mechanism for the renal diuresis and natriuresis may be a decrease in renal sympathetic nerve activity in L-arginine-treated rats as a similar natriuresis and diuresis occurred following renal denervation (Kanno et al. 1992).

The urinary sodium to potassium ratio in the L-arginine-treated rats was significantly increased. As this ratio is inversely proportional to plasma aldosterone level (Williams and Dluhy 1972), it suggests a reduction in aldosterone secretion under these conditions (Saxena et al. 2018). Aldosterone is secreted from the adrenal cortex as a consequence of direct stimulation by angiotensin II. Therefore, the urinary sodium to potassium ratio can be taken as a surrogate marker of angiotensin II level in the circulatory system and can indirectly impact on the control of blood pressure.

Despite the fact that L-arginine administration increased glomerular filtration rate (creatinine clearance), renal cortical blood perfusion was significantly decreased compared to untreated control rats which might be due to a decreased cardiac output. Nevertheless, other investigators have also reported no effect of L-arginine on renal plasma flow in hypertensive and normal human subjects (Ebel et al. 1993, Barri and Wilcox 1998). While other recent reports also include estimates of GFR as well as PWV as major indices of arterial stiffness, they emerge as significant predictors of cardiovascular risk (Safar et al. 2015). The low renal cortical blood perfusion in L-arginine-treated rats could be due to the reduced PWV leading to enhancement of arterial distensibility which indirectly lowered blood pressure and hence perfusion pressure in the kidney. L-arginine treatment in normotensive rats increased the kidney index and caused renal injury as reflected by a marked arteriolar congestion in the glomeruli accompanied with mild ischemic tubular congestion. These histopathological findings together with the occurrence of increased urinary protein excretion resulting from chronic administration of L-arginine are consistent with renal damage.

Interestingly, treatment with apocynin or combination of apocynin and catalase for 14 days elicited a restorative effect on renal function and renal histology. A similar protective effect of apocynin has been reported previously (Ciarcia et al. 2015). This effect could be due to the suppression of the oxidative stress mechanisms induced by L-arginine via the strong $\mathrm{O}_{2}{ }^{--}$scavenging 
properties of apocynin (Altintas et al. 2013). However, the catalase treatment in L-arginine rats showed only a partial restoration of these parameters as the histological changes consistent with mild tubular injury were still present. This could possibly be explained by the fact that the concomitant catalyzation of $\mathrm{H}_{2} \mathrm{O}_{2}$ to $\mathrm{H}_{2} \mathrm{O}$ and $\mathrm{O}_{2}$ would lead to the accumulation of $\mathrm{O}_{2}$ which could further react with excess $\mathrm{NO}$ to form $\mathrm{ONOO}^{-}$which is a strong nitrosative oxidant that can cause lipid peroxidation (Beckman and Koppenol 1996).

There is evidence that continuous exposure to L-arginine itself induces oxidative stress in cultured human endothelial cells (Mohan et al. 2012). Moreover, NO is considered to have antioxidant as well as pro-oxidant properties depending on the experimental protocols (Hiramoto et al. 2003) and dose of the NO used (Joshi et al. 1999). To evaluate the impact of L-arginine administration on oxidative stress in the present experimental scenario, oxidative stress markers were measured. It was evident that 14 days of oral administration of L-arginine induced oxidative stress reflected by a $51 \%$ increase in plasma NO. Oxidative stress was characterized by increased of plasma MDA levels and decreased plasma T-SOD and T-AOC. However, L-arginine administration together with apocynin and combined apocynin plus catalase significantly ameliorated the oxidative stress which was much less when only catalase was given. The mechanisms underlying how plasma NO could be normalized by apocynin in L-arginine-treated rats are not at all clear. However, one possibility may be that apocynin is a stronger antioxidant than catalase as the $\mathrm{O}_{2}{ }^{--}$scavenging action by apocynin successfully lowered plasma MDA and NO levels with concomitant increases in plasma T-SOD and T-AOC. However, treatment with catalase alone led to a heightened plasma MDA which might explain the elevation in lipid peroxidation possibly due to the accumulation of $\mathrm{ONOO}^{-}$and the spontaneous generation of excess $\mathrm{NO}$ and $\mathrm{O}_{2}{ }^{-}$(Halliwell et al. 1999, Radi et al. 2002).

Nox 4 is widely distributed in the vascular smooth muscle cells of the kidney (Johns et al. 2010) and the present findings demonstrated that L-arginine administration increased Nox4 mRNA expression in the renal homogenates by 2.1 fold, a response that was offset by concomitant apocynin treatment. This was possibly due to apocynin inhibiting the association of the active Nox4 complex by preventing translocation of the cytosolic subunits to the membrane-bound catalytic subunit (Johnson et al. 2002). Apocynin treatment successfully reversed the endothelial NO dysfunction in both animals and humans exposed to oxidative stress (Hamilton et al. 2004). The co-administration of apocynin and catalase had a greater ability to supress Nox4 mRNA than either apocynin or catalase alone. This could be possibly due to the crosstalk between the direct $\mathrm{O}_{2}^{*-}$ elimination by apocynin and continuous $\mathrm{H}_{2} \mathrm{O}_{2}$ catalysation of catalase enzyme. The mechanism by which these antioxidants restore Nox 4 activity is not fully understood, but it has been suggested that apocynin and catalase could act by preventing the translocation of the cytosolic phagocyte oxidase subunits (Johns et al. 2010). Apocynin inhibits the release of $\mathrm{O}_{2}{ }^{--}$by NADPH oxidase by blocking migration of $\mathrm{p} 47^{\text {phox }}$ to the membrane which is critically involved in initiating assembly of the functional NADPH oxidase complex (Touyz 2008).

In conclusion, oral administration of L-arginine for 14 days has an acute systemic hypotensive effect in normotensive rats which appeared to be mediated by increased endogenous NO production. The increased NO bioavailability resulted in oxidative stress accompanied by renal functional and histological alterations with a concomitant increase of renal Nox4 mRNA expression in the L-arginine-treated rats. The present study indicated that prophylactic treatment with apocynin and combined apocynin plus catalase for 14 days not only restored blood pressure and heart rate near to control levels but also normalized the renal functional parameters and successfully halted the L-arginine-induced histological damage. Apocynin, but not catalase, inhibited NADPH oxidase Nox4 subunit expression and decreased indicators of oxidative stress. This knowledge may open up novel treatment options for clinicians and patients in disease states associated with oxidative stress.

\section{Conflict of Interest}

There is no conflict of interest.

\section{Acknowledgements}

Universiti Sains Malaysia is acknowledged for Research Grants to M.A.S. We also thank The Institute of Postgraduate Studies (IPS) of Universiti Sains Malaysia for providing a research fellowship to T.Y.C. The Pantai Premier Pathology Sdn. Bhd. is acknowledged for the professional service and advice on histopathology studies. This study was funded by the Research Universiti grant from Universiti Sains Malaysia number 1001/PFARMASI/811347 to M.A.S. 


\section{References}

AHMAD A, SATTAR MA, AZAM M, KHAN SA, BHATT O, JOHNS EJ: Interaction between nitric oxide and renal alpha1-adrenoreceptors mediated vasoconstriction in rats with left ventricular hypertrophyin Wistar Kyoto rats. PloS One 13: e0189386, 2018. https://doi.org/10.1371/journal.pone.0189386

AHMAD A, SATTAR MA, RATHORE HA, ABDULLA MH, KHAN SA, ABDULLAH NA, JOHNS EJ: Enhanced expression of endothelial nitric oxide synthase in the myocardium ameliorates the progression of left ventricular hypertrophy in L-arginine treated Wistar-Kyoto rats. J Physiol Pharmacol 67: 31-44, 2016.

AHMAD A, SATTAR MA, RATHORE HA, ABDULLA MH, KHAN SA, AZAM M, ABDULLAH NA, JOHNS EJ: Up regulation of cystathione y lyase and hydrogen sulphide in the myocardium inhibits the progression of isoproterenol-caffeine induced left ventricular hypertrophy in Wistar Kyoto rats. PloS One 11: e0150137, 2016. https://doi.org/10.1371/journal.pone.0150137

AHMAD FUD, SATTAR MA, RATHORE HA, TAN YC, AKHTAR S, JIN OH, PEI YP, ABDULLAH NA, JOHNS EJ: Hydrogen sulphide and tempol treatments improve the blood pressure and renal excretory responses in spontaneously hypertensive rats. Ren Fail 36: 598-605, 2014. https://doi.org/10.3109/0886022X.2014.882218

ALDERTON WK, COOPER CE, KNOWLES RG: Nitric oxide synthases: structure, function and inhibition. Biochem J 357: 593-615, 2001. https://doi.org/10.1042/bj3570593

ALTINTAS R, POLAT A, VARDI N, OGUZ F, BEYTUR A, SAGIR M, YILDIZ A, PARLAKPINAR H: The protective effects of apocynin on kidney damage caused by renal ischemia/reperfusion. J Endourol 27 : 617-624, 2013. https://doi.org/10.1089/end.2012.0556

ARCHER S: Measurement of nitric oxide in biological models. FASEB J 7: 349-360, 1993. https://doi.org/10.1096/fasebj.7.2.8440411

ARIKAWE AP, UDENZE IC, OLUSANYA AW, AKINNIBOSUN OA, DIKE I, DURU BN: L-arginine supplementation lowers blood pressure, protein excretion and plasma lipid profile in experimental salt-induced hypertension in pregnancy: Relevance to preeclampsia. Pathophysiology 26: 191-197, 2019. https://doi.org/10.1016/j.pathophys.2019.02.002

BARRI YM, WILCOX CS: Salt intake determines the renal response to L-arginine infusion in normal human subjects. Kidney Int 53: 1299-1304, 1998. https://doi.org/10.1046/j.1523-1755.1998.00857.x

BECKMAN JS, KOPPENOL WH: Nitric oxide, superoxide, and peroxynitrite: the good, the bad, and ugly. Am J Physiol Cell Physiol 271: C1424-C1437, 1996. https://doi.org/10.1152/ajpcell.1996.271.5.C1424

CADENAS E, DAVIES KJA: Mitochondrial free radical generation, oxidative stress, and aging. Free Radic Biol Med 29: 222-230, 2000. https://doi.org/10.1016/S0891-5849(00)00317-8

CIARCIA R, DAMIANO S, FLORIO A, SPAGNUOLO M, ZACCHIA E, SQUILLACIOTI C, MIRABELLA N, FLORIO S, PAGNINI U, GAROFANO T: The protective effect of apocynin on cyclosporine A-induced hypertension and nephrotoxicity in rats. $\mathrm{J}$ Cell Biochem 116: 1848-1856, 2015. https://doi.org/10.1002/jcb.25140

DARLEY-USMAR V, WISEMAN H, HALLIWELL B: Nitric oxide and oxygen radicals: a question of balance. FEBS Lett 369: 131-135, 1995. https://doi.org/10.1016/0014-5793(95)00764-Z

DENG W, ABLIZ A, XU S, SUN R, GUO W, SHI Q, YU J, WANG W: Severity of pancreatitis-associated intestinal mucosal barrier injury is reduced following treatment with the NADPH oxidase inhibitor apocynin. Mol Med Rep 14: 3525-3534, 2016. https://doi.org/10.3892/mmr.2016.5678

EBEL M, CATAPANO G, COLOMBO MG, CLERICO A, GIANNESSI D, DEL CHICCA M, LUPETTI S, MATERAZZI F, PEDRINELLI R: The humoral, renal and pressor effects of systemic l-arginine infusion in hypertensive patients. J Hypertens 11: S140-S141, 1993. https://doi.org/10.1097/00004872-199312050-00049

HALLIWELL B, ZHAO K, WHITEMAN M: Nitric oxide and peroxynitrite. The ugly, the uglier and the not so good: a personal view of recent controversies. Free Radic Res 31: 651-669, 1999. https://doi.org/10.1080/10715769900301221

HAMILTON CA, MILLER WH, SAMMY A-B, BROSNAN MJ, DRUMMOND RD, MCBRIDE MW, DOMINICZAK AF: Strategies to reduce oxidative stress in cardiovascular disease. Clin Sci 106: 219-234, 2004. https://doi.org/10.1042/CS20030379 
HERLITZ H, JUNGERSTEN LU, WIKSTRAND J, WIDGREN BR: Effect of L-arginine infusion in normotensive subjects with and without a family history of hypertension. Kidney Int 56: 1838-1845, 1999. https://doi.org/10.1046/j.1523-1755.1999.00735.x

HIRAMOTO K, OHKAWA T, OIKAWA N, KIKUGAWA K: Is nitric oxide (NO) an antioxidant or a prooxidant for lipid peroxidation? Chem Pharm Bull 51: 1046-1050, 2003. https://doi.org/10.1248/cpb.51.1046

HU L, ZHANG Y, LIM PS, MIAO Y, TAN C, MCKENZIE KUS, SCHYVENS CG, WHITWORTH JA: Apocynin but not L-arginine prevents and reverses dexamethasone-induced hypertension in the rat. Am J Hypertens 19: 413-418, 2006. https://doi.org/10.1016/j.amjhyper.2005.09.023

IMPELLIZZERI D, ESPOSITO E, MAZZON E, PATERNITI I, DI PAOLA R, BRAMANTI P, CUZZOCREA S: Effect of apocynin, a NADPH oxidase inhibitor, on acute lung inflammation. Biochem Pharmacol 81: 636-648, 2011. https://doi.org/10.1016/j.bcp.2010.12.006

JOHNS EJ, O'SHAUGHNESSY B, O'NEILL S, LANE B, HEALY V: Impact of elevated dietary sodium intake on $\mathrm{NAD}(\mathrm{P}) \mathrm{H}$ oxidase and SOD in the cortex and medulla of the rat kidney. Am J Physiol Regul Integr Comp Physiol 299: R234-R240, 2010. https://doi.org/10.1152/ajpregu.00541.2009

JOSHI MS, PONTHIER JL, LANCASTER JR: Cellular antioxidant and pro-oxidant actions of nitric oxide. Free Radic Biol Med 27: 1357-1366, 1999. https://doi.org/10.1016/S0891-5849(99)00179-3

KANNO K, HIRATA Y, EMORI T, OHTA K, EGUCHI S, IMAI T, MARUMO F: L-arginine infusion induces hypotension and diuresis/natriuresis with concomitant increased urinary excretion of nitrite/nitrate and cyclic GMP in humans. Clin Exp Pharmacol Physiol 19: 619-625, 1992. https://doi.org/10.1111/j.14401681.1992.tb00514.x

KAUR J, VRANISH JR, FADEL PJ: L-arginine infusion reduces muscle sympathetic nerve activity and blood pressure in patients with chronic kidney disease. FASEB J 31: 863-866, 2017. https://doi.org/10.1096/fasebj.31.1 supplement.863.6

KITIYAKARA C, CHABRASHVILI T, CHEN Y, BLAU J, KARBER A, ASLAM S, WELCH WJ, WILCOX CS: Salt intake, oxidative stress, and renal expression of NADPH oxidase and superoxide dismutase. J Am Soc Nephrol 14: 2775-2782, 2003. https://doi.org/10.1097/01.ASN.0000092145.90389.65

LIAUDET L, SORIANO FG, SZABO C: Biology of nitric oxide signaling. Crit Care Med 28: N37-N52, 2000. https://doi.org/10.1097/00003246-200004001-00005

LIVAK KJ, SCHMITTGEN TD: Analysis of relative gene expression data using real-time quantitative PCR and the $2^{-\triangle \Delta C T}$ method. Methods 25: 402-408, 2001. https://doi.org/10.1006/meth.2001.1262

MEHTA S, STEWART DJ, LEVY RD: The hypotensive effect of L-arginine is associated with increased expired nitric oxide in humans. Chest 109: 1550-1555, 1996. https://doi.org/10.1378/chest.109.6.1550

MILLER NJ, RICE-EVANS C, DAVIES MJ, GOPINATHAN V, MILNER A: A novel method for measuring antioxidant capacity and its application to monitoring the antioxidant status in premature neonates. Clin Sci 84 : 407-412, 1993. https://doi.org/10.1042/cs0840407

MOHAN S, WU C-C, SHIN S, FUNG H-L: Continuous exposure to L-arginine induces oxidative stress and physiological tolerance in cultured human endothelial cells. Amino Acids 43: 1179-1188, 2012. https://doi.org/10.1007/s00726-011-1173-y

MONCADA S, HIGGS EA: Molecular mechanisms and therapeutic strategies related to nitric oxide. FASEB J 9: 1319-1330, 1995. https://doi.org/10.1096/fasebj.9.13.7557022

OHKAWA H, OHISHI N, YAGI K: Assay for lipid peroxides in animal tissues by thiobarbituric acid reaction. Anal Biochem 95: 351-358, 1979. https://doi.org/10.1016/0003-2697(79)90738-3

OKAMOTO H, HOKA S, KAWASAKI T, OKUYAMA T, TAKAHASHI S: L-arginine attenuates ketamine-induced increase in renal sympathetic nerve activity. Anesthesiology 81: 137-146, 1994. https://doi.org/10.1097/00000542-199407000-00020

ORTIZ MC, BORGHESE MFA, BALONGA SE, LAVAGNA A, FILIPUZZI AL, ELESGARAY R, COSTA MA, MAJOWICZ MP: Renal response to L-arginine in diabetic rats. A possible link between nitric oxide system and aquaporin-2. PloS One 9: e104923, 2014. https://doi.org/10.1371/journal.pone.0104923

OYANAGUI Y: Reevaluation of assay methods and establishment of kit for superoxide dismutase activity. Anal Biochem 142: 290-296, 1984. https://doi.org/10.1016/0003-2697(84)90467-6 
PECHANOVA O, DOBESOVA Z, CEJKA J, KUNES J, ZICHA J: Vasoactive systems in L-NAME hypertension: the role of inducible nitric oxide synthase. J Hypertens 22: 167-173, 2004. https://doi.org/10.1097/00004872$\underline{200401000-00026}$

RACASAN S, BRAAM B, VAN DER GIEZEN DM, GOLDSCHMEDING R, BOER P, KOOMANS HA, JOLES JA: Perinatal L-arginine and antioxidant supplements reduce adult blood pressure in spontaneously hypertensive rats. Hypertension 44: 83-88, 2004. https://doi.org/10.1161/01.HYP.0000133251.40322.20

RADI R, CASSINA A, HODARA R, QUIJANO C, CASTRO L: Peroxynitrite reactions and formation in mitochondria. Free Radic Biol Med 33: 1451-1464, 2002. https://doi.org/10.1016/S0891-5849(02)01111-5

SAFAR ME, PLANTE GE, MIMRAN A: Arterial stiffness, pulse pressure, and the kidney. Am J Hypertens 28 : 561-569, 2015. https://doi.org/10.1093/ajh/hpu206

SANDER M, HANSEN J, VICTOR RG: The sympathetic nervous system is involved in the maintenance but not

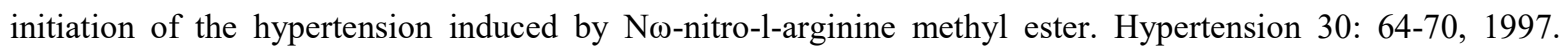
https://doi.org/10.1161/01.HYP.30.1.64

SAXENA T, ALI AO, SAXENA M: Pathophysiology of essential hypertension: an update. Expert Rev Cardiovasc Ther 16: 879-887, 2018. https://doi.org/10.1080/14779072.2018.1540301

SINHA N, KUMAR DABLA P: Oxidative stress and antioxidants in hypertension-a current review. Curr Hypertens Rev 11: 132-142, 2015. https://doi.org/10.2174/1573402111666150529130922

SWARUP KRLA, SATTAR MA, ABDULLAH NA, ABDULLA MH, SALMAN IM, RATHORE HA, JOHNS EJ: Effect of dragon fruit extract on oxidative stress and aortic stiffness in streptozotocin-induced diabetes in rats. Pharmacogn Res 2: 31-35, 2010. https://doi.org/10.4103/0974-8490.60582

TAN B, YIN Y, LIU Z, LI X, XU H, KONG X, HUANG R, TANG W, SHINZATO I, SMITH SB: Dietary L-arginine supplementation increases muscle gain and reduces body fat mass in growing-finishing pigs. Amino acids 37 : 169-175, 2009. https://doi.org/10.1007/s00726-008-0148-0

TOUSOULIS D, KAMPOLI A-M, TENTOLOURIS NIKOLAOS PAPAGEORGIOU C, STEFANADIS C: The role of nitric oxide on endothelial function. Curr Vasc Pharmacol 10: 4-18, 2012. https://doi.org/10.2174/157016112798829760

TOUYZ RM: Apocynin, NADPH oxidase, and vascular cells: a complex matter. J Hypertens 51:172-174, 2008. https://doi.org/10.1161/HYPERTENSIONAHA.107.103200

TUNCTAN B, KORKMAZ B, YILDIRIM H, TAMER L, ATIK U, BUHARALIOGLU CK: Reversal of endotoxininduced hypotension by inhibition of inducible nitric oxide synthase activity is associated with improved oxidative status in rat heart, aorta and mesenteric artery. Turk J Med Sci 36: 71-80, 2006.

WANG D, WEI J, HSU K, JAU J-C, LIEU M-W, CHAO T-J, CHEN HI: Effects of nitric oxide synthase inhibitors on systemic hypotension, cytokines and inducible nitric oxide synthase expression and lung injury following endotoxin administration in rats. J Biomed Sci 6: 28-35, 1999. https://doi.org/10.1007/BF02256421

WANG YX, HALKS-MILLER M, VERGONA R, SULLIVAN ME, FITCH R, MALLARI C, MARTIN-MCNULTY B, DA CUNHA V, FREAY A, RUBANYI GM: Increased aortic stiffness assessed by pulse wave velocity in apolipoprotein E-deficient mice. Am J Physiol Heart Circ Physiol 278: H428-H434, 2000. https://doi.org/10.1152/ajpheart.2000.278.2.H428

WEDGWOOD S, LAKSHMINRUSIMHA S, FARROW KN, CZECH L, GUGINO SF, SOARES F, RUSSELL JA, STEINHORN RH: Apocynin improves oxygenation and increases eNOS in persistent pulmonary hypertension of the newborn. Am J Physiol Lung Cell Mol Physiol 302: L616-L626, 2011. https://doi.org/10.1152/ajplung.00064.2011

WILLIAMS GH, DLUHY RG: Aldosterone biosynthesis: interrelationship of regulatory factors. Am J Med 53: 595605, 1972. https://doi.org/10.1016/0002-9343(72)90156-8

WOLZT M, SCHMETTERER L, FERBER W, ARTNER E, MENSIK C, EICHLER HG, KREJCY K: Effect of nitric oxide synthase inhibition on renal hemodynamics in humans: reversal by L-arginine. Am J Physiol Renal Physiol 272: F178-F182, 1997. https://doi.org/10.1152/ajprenal.1997.272.2.F178

ZHAO J, WECHT JM, ZHANG Y, WEN X, ZEMAN R, BAUMAN WA, CARDOZO C: iNOS expression in rat aorta is increased after spinal cord transection: a possible cause of orthostatic hypotension in man. Neurosci Lett 415: 210-214, 2007. https://doi.org/10.1016/j.neulet.2007.01.025 
ZHOU M-S, KOSAKA H, TIAN R-X, ABE Y, CHEN Q-H, YONEYAMA H, YAMAMOTO A, ZHANG L: L-Arginine improves endothelial function in renal artery of hypertensive Dahl rats. J Hypertens 19: 421-429, 2001. https://doi.org/10.1097/00004872-200103000-00010 